\title{
Comparison between the next generation impactor and the twin glass impinge as model pulmonary drug delivery devices
}

\begin{tabular}{ccc}
\hline Huner Kamal Omer* & Nozad Rashid Husein* & Hewa Abdulla Hamadameen* \\
\hline Abstract
\end{tabular}

Background and objective: The British Pharmacopoeia contains four apparatus for testing inhalers. Two of these are the next generation impactor, and the twin glass impinge which differs in their use. The next generation impactor apparatus should ideally have at least five stages; even though the twin glass impinge has only two stages, it is still listed in the British Pharmacopoeia. The next generation impactor is more accurate, reliable and sophisticated than the twin glass impinger. This study gives a detailed comparison of the two pieces of equipment.

Methods: Carriers including mannitol, lactose monohydrate, trehalose and sucrose with active pharmaceutical ingredient; salbutamol sulphate were delivered by dry powder inhaler using the next generation impactor and twin glass impinger at a constant flow rate of $60 \mathrm{~L} / \mathrm{min}$.

Results: The twin glass impinge respirable fractions of the powders were higher than the next generation impactor for each carrier. As expected, mannitol powder had the lowest percentage remaining in the capsule compared to lactose monohydrate, trehalose and sucrose had the greatest percentage remaining for both inhaler devices.

Conclusion: Even though both apparatus are important for in-vitro studies of drug delivery into the lungs using inhaler devices, the next generation impactor is better suited when a specific size range is required. The twin glass impinger is useful for simple inhaler testing, and the inclusion within the British Pharmacopoeia is justified.

Keywords: Twin glass impinge; Next generation impactor; Dry powder inhaler.

\section{Introduction}

For the aerodynamic assessment of fine particles and characteristics, the British Pharmacopeia (BP) allows the use of four different apparatus. These include the twin glass impinger, multi-stage liquid impinger, Anderson cascade impactor (ACl) and next generation impactor (NGI). Impactors collect particles as they 'impact' on a dry impaction plate or cup. Impingers, in comparison, consists of a liquid collection surface. ${ }^{1}$ Using these apparatuses to the standards of the BP, a direct link can be made with the mass of therapeutically active pharmaceutical ingredient (API) and particle aerodynamic size. This can be used as an indication of where deposition occurs in the respiratory tract. $^{2}$ The twin glass impinger is used for research in academia due to its simplicity, ease of operation and assembles. It is a two-stage separation device which divides the dose emitted into respirable and non-respirable portions. The upper region mimics the oropharynx and throat, and a lower region as the deep lungs. ${ }^{3}$ The next generation impactor is a new product designed to be used by pharmaceutical industries for the testing of inhalers. ${ }^{4,5}$ The $\mathrm{NGI}$ provides an alternative to the $\mathrm{ACl}$ and is less labor-intensive. The NGI consists of eight nozzle pieces corresponding to seven size-fractionation stages and a microorifice collector (MOC) that collects extremely small particles, which requires a filter in other impactors. At a flow rate of $60 \mathrm{~L} / \mathrm{min}$, the cut-off stages 1 to 7 is $8.06 \mu \mathrm{m}, 4.46 \mu \mathrm{m}, 2.82 \mu \mathrm{m}$,

* Department of Pharmaceutics, College of Pharmacy, Hawler Medical University, Erbil, I raq. 
$1.66 \mu \mathrm{m}, 0.94 \mu \mathrm{m}, 0.55 \mu \mathrm{m}$, and $0.34 \mu \mathrm{m}$, respectively. ${ }^{6}$ The NGI is coupled with an induction port and a pre-separator in inhaler testing. The purpose of the induction port is to mimic the oropharynx of an adult, whereas the pre-separators used to capture carrier-bound API particles which are much larger than carrier-free API particle. ${ }^{7}$ Salbutamol sulphate is a bronchodilator which dilates the bronchi and bronchioles for the treatment of short-term asthmatic patients. ${ }^{8,9}$ The optimum particle size required for deposition into deep lungs is 2-6 $\mu \mathrm{m} .{ }^{10}$ Carriers are used to enhance the powder flow which improves the dosing accuracy of the drugs. ${ }^{11}$ This study compares the in-vitro testing of the amount of drug delivery between the twin glass impinger and the next generation impactor using a dry powder inhaler. It also compares the delivery efficiency of four different carriers including mannitol, lactose monohydrate, trehalose and sucrose of the drug into the lungs.

\section{Methods}

Firstly, the twin glass impinge was tested. Each experiment used two capsules, and each containing $25 \mathrm{mg}$ of the powder were weighed. The flow rate was adjusted to $60 \mathrm{~L} / \mathrm{min}$ using Critical Flow Controller Model TPK 2000 and Flow Meter Model DFM 2000 (Copley Scientific Limited, Nottingham, UK). At this flow rate, the cut-off aerodynamic diameter between the upper and lower stages of the impinger is $6.4 \mu \mathrm{m}$. Particles below this size will deposit in the lower stage and regarded -respirable" or in -fine particle fraction (FPF)". ${ }^{3}$ Two capsules each containing approximately $25 \mathrm{mg}$ of the powdered formulation were loaded into size 3 hydroxypropyl methylcellulose (HPMC) capsulesindividually installed in the inhaler device. The monodose inhaler device was attached to the impinger containing 7 and $30 \mathrm{ml}$ of deionized water in stages 1 and 2 , respectively to collect the aerosolized powder. Each capsule was actuated from the inhaler over $5 \mathrm{sec}$ for each measurement. After inspiration, the glass impinger was dismantled, and each stage, the inhaler device, and emptied capsules were separately washed with appropriate volumes of deionized water and placed into volumetric flasks. Three independent experiments were conducted for each formulation using three different batches. The amount of powder collected from each compartment was determined using high-performance liquid chromatography (HPLC). Secondly, the experiment tested the NGI. Two hydroxyl propyl methyl cellulose (HPMC) hard capsules (size 3, Qualicaps, Spain) were loaded with $25 \mathrm{mg}$ of powder which was then loaded into DPI device, the Miat ${ }^{\circledR}$ Monodose inhaler (Miat S.P.A., Milan, Italy) which was then tightly fitted into the induction port. The NGI was run at a controlled flow rate $(\mathrm{Q})$ of $60 \mathrm{~L} / \mathrm{min}$ with a delay time of $10 \mathrm{sec}$ (NGI Flow controller) prior to the capsules being needle-pierced within the device, where the particles were drawn into the impactor for $10 \mathrm{sec}$. This was done with two capsules per sample for a total of $50 \mathrm{mg}$ total per run. For each $50 \mathrm{mg}$ run, the amount of particles deposited onto each stage was determined by washing the relevant stage with deionized water. Experiments were performed in triplicates and values expressed as mean \pm standard deviations. Statistical significance was assessed using one-way analysis of variance (ANOVA) and student t-tests. A $P$ value of $<0.05$ indicates that the difference is statistically significant.

\section{Results}

The results obtained from HPLC analysis were multiplied by the dilution factor and divided by the amount of drug put into the formulation. This gave the amount of drug deposited in each section of the apparatus. An average and the standard deviation were calculated for each carrier. Tables 1 and 2 illustrate the average percentage of the drug deposited in each section of the twin glass impinge and NGI respectively. 
The percentage of powder remained in the capsule were lower $(P=0.003)$ for mannitol formulation compared to lactose, trehalose and sucrose formulations of the twin glass impinge and $\mathrm{NGI}$, respectively. In contrast, the fraction of powder deposited in the lower part of impinger and impactor were lower $(P<0.001)$ for mannitol compared to other carriers which indicate the higher deposition of mannitol in the upper compartments. Since the twin glass impinges canonly able to separate the deposited dose into respirable (lower part), and non-respirable dose (upper part), the sections from the $\mathrm{NGI}$ were also grouped into respirable and non-respirable doses. The mouthpiece, induction port, pre -separator, $1^{\text {st }}$, and $2^{\text {nd }}$ cups were grouped into the non-respirable dose. Any deposited dose from the $3^{\text {rd }}$ cup to the MOC was grouped into the respirable dose. Table 3 shows a comparison between the respirable and non-respirable doses observed for all of the four carriers with the two apparatus.

Table 1: Average percentage of drug deposited with different carriers in each compartment of the twin glass impinger.

\begin{tabular}{|c|c|c|c|c|c|}
\hline Compartments & Mannitol (\%) & Lactose (\%) & Trehalose (\%) & Sucrose (\%) & $P$ value \\
\hline \multirow[t]{2}{*}{ Capsules } & 1.19 & 7.56 & 11.08 & 5.52 & 0.003 \\
\hline & \pm 0.67 & \pm 2.88 & \pm 2.83 & \pm 1.65 & \\
\hline \multirow[t]{2}{*}{ Device } & 7.15 & 19.58 & 24.76 & 8.23 & 0.001 \\
\hline & \pm 1.72 & \pm 7.28 & \pm 2.08 & \pm 2.84 & \\
\hline \multirow[t]{2}{*}{ Upper } & 64.16 & 26.37 & 19.09 & 38.51 & $<0.001$ \\
\hline & \pm 5.46 & \pm 13.38 & \pm 4.47 & \pm 2.89 & \\
\hline \multirow[t]{2}{*}{ Lower } & 27.50 & 46.48 & 45.08 & 47.74 & $<0.001$ \\
\hline & \pm 3.75 & \pm 3.81 & \pm 1.22 & \pm 0.73 & \\
\hline
\end{tabular}

Table 2: Average percentage of drug deposited with different carriers in each section of the NGI with the standard deviations

\begin{tabular}{|c|c|c|c|c|c|}
\hline Compartments & Mannitol (\%) & Lactose (\%) & Trehalose (\%) & Sucrose (\%) & $P$ value \\
\hline Capsule & $\begin{array}{c}1.35 \\
\pm 0.35\end{array}$ & $\begin{array}{l}15.52 \\
\pm 4.26\end{array}$ & $\begin{array}{c}7.00 \\
\pm 1.56\end{array}$ & $\begin{array}{l}10.02 \\
\pm 8.32\end{array}$ & 0.036 \\
\hline Device & $\begin{array}{l}10.20 \\
\pm 1.51\end{array}$ & $\begin{array}{c}26.82 \\
\pm 11.59\end{array}$ & $\begin{array}{l}29.18 \\
\pm 9.03\end{array}$ & $\begin{array}{l}10.84 \\
\pm 1.23\end{array}$ & 0.022 \\
\hline Mouth piece & $\begin{array}{l}32.52 \\
\pm 6.19\end{array}$ & $\begin{array}{r}7.45 \\
\pm 3.19\end{array}$ & $\begin{array}{c}7.55 \\
\pm 2.62\end{array}$ & $\begin{array}{l}10.96 \\
\pm 1.43\end{array}$ & $<0.001$ \\
\hline Preseparator & $\begin{array}{l}19.59 \\
\pm 2.74\end{array}$ & $\begin{array}{l}10.61 \\
\pm 3.39\end{array}$ & $\begin{array}{l}12.47 \\
\pm 8.69\end{array}$ & $\begin{array}{l}14.39 \\
\pm 7.84\end{array}$ & 0.385 \\
\hline $1^{\text {st }}$ & $\begin{array}{c}7.87 \\
\pm 1.68\end{array}$ & $\begin{array}{c}1.41 \\
\pm 0.41\end{array}$ & $\begin{array}{r}1.58 \\
\pm 0.16\end{array}$ & $\begin{array}{c}3.85 \\
\pm 0.02\end{array}$ & $<0.001$ \\
\hline $2^{\text {nd }}$ & $\begin{array}{l}14.97 \\
\pm 2.82\end{array}$ & $\begin{array}{c}7.16 \\
\pm 1.38\end{array}$ & $\begin{array}{r}8.94 \\
\pm 1.02\end{array}$ & $\begin{array}{l}17.91 \\
\pm 1.97\end{array}$ & $<0.001$ \\
\hline $3^{\text {rd }}$ & $\begin{array}{c}7.98 \\
\pm 1.03\end{array}$ & $\begin{array}{l}11.53 \\
\pm 2.47\end{array}$ & $\begin{array}{l}11.08 \\
\pm 0.26\end{array}$ & $\begin{array}{l}15.55 \\
\pm 1.81\end{array}$ & 0.003 \\
\hline $4^{\text {th }}$ & $\begin{array}{c}4.01 \\
\pm 0.64\end{array}$ & $\begin{array}{l}11.75 \\
\pm 3.43\end{array}$ & $\begin{array}{l}13.64 \\
\pm 0.97\end{array}$ & $\begin{array}{l}11.63 \\
\pm 0.43\end{array}$ & $<0.001$ \\
\hline $5^{\text {th }}$ & $\begin{array}{c}0.90 \\
\pm 0.09\end{array}$ & $\begin{array}{r}4.96 \\
\pm 1.30\end{array}$ & $\begin{array}{r}5.41 \\
\pm 1.10\end{array}$ & $\begin{array}{c}2.91 \\
\pm 0.39\end{array}$ & $<0.001$ \\
\hline $6^{\text {th }}$ & $\begin{array}{c}0.29 \\
\pm 0.04\end{array}$ & $\begin{array}{c}1.60 \\
\pm 0.22\end{array}$ & $\begin{array}{c}1.94 \\
\pm 0.17\end{array}$ & $\begin{array}{c}1.03 \\
\pm 0.09\end{array}$ & $<0.001$ \\
\hline $7^{\text {th }}$ & $\begin{array}{c}0.20 \\
\pm 0.03\end{array}$ & $\begin{array}{c}0.79 \\
\pm 0.23\end{array}$ & $\begin{array}{c}0.80 \\
\pm 0.22\end{array}$ & $\begin{array}{c}0.55 \\
\pm 0.05\end{array}$ & 0.005 \\
\hline MOC & $\begin{array}{c}0.13 \\
\pm 0.00\end{array}$ & $\begin{array}{c}0.30 \\
\pm 0.06\end{array}$ & $\begin{array}{c}0.40 \\
\pm 0.05\end{array}$ & $\begin{array}{c}0.35 \\
\pm 0.05\end{array}$ & $<0.001$ \\
\hline
\end{tabular}


Results from Table 3 shows that the respirable fraction of twin glass impinger was higher $(P=0.041)$ than values for $\mathrm{NGI}$. Moreover, no significant differences $(P>0.05)$ were found between the amount of powders deposited in the capsule $(P=0.663)$, device $(P=0.603)$ and non-respirable $(P=0.560)$ compartments. A further comparison can be made when observing the respirable and non-respirable doses of each carrier individually. Both pieces of equipment were also grouped in the same way. Table 4 shows a comparison between the respirable and non-respirable doses for each carrier tested with the twin glass impinger and the NGI. Table 4 elucidates that the respirable fraction for twin glass impinger was significantly higher than the values for $\mathrm{NGI}$ in all carriers. Furthermore, the results revealed no significant differences between twin glass impinger and $\mathrm{NGI}$ for the amount of powders deposited in the capsule, device and non-respirable compartments.

Table 3: Comparison between the respirable and non-respirable dose observed using the average of all four carriers with the twin glass impinger and the NGI.

\begin{tabular}{lccc}
\hline Compartments & Twin Glass Impinger (\%) & NGI (\%) & P value \\
\hline Capsules & 6.34 & 8.34 & 0.663 \\
& \pm 4.13 & \pm 6.13 & \\
Device & 14.93 & 19.26 & 0.603 \\
& \pm 8.63 & \pm 10.14 & \\
Non-respirable & 37.03 & 44.81 & 0.560 \\
& \pm 19.78 & \pm 7.74 & \\
Respirable & 41.70 & 27.45 & 0.041 \\
& \pm 6.53 & \pm 5.14 & \\
\hline
\end{tabular}

Table 4: Comparison between the respirable and non-respirable dose for each carrier with the twin glass impinger and the NGI.

\begin{tabular}{|c|c|c|c|c|c|c|c|c|c|c|c|c|}
\hline Compartments & $\begin{array}{l}\text { Mannitol } \\
\text { - Twin } \\
\text { Glass } \\
\text { Impinger }\end{array}$ & $\begin{array}{l}\text { Mannitol } \\
-\mathrm{NGI}\end{array}$ & $\begin{array}{c}P \\
\text { value }\end{array}$ & $\begin{array}{l}\text { Lactose - } \\
\text { Twin } \\
\text { Glass } \\
\text { Impinger }\end{array}$ & $\begin{array}{l}\text { Lactose } \\
- \text { NGI }\end{array}$ & $\begin{array}{c}P \\
\text { value }\end{array}$ & $\begin{array}{l}\text { Trehalose } \\
\text { - Twin } \\
\text { Glass } \\
\text { Impinger }\end{array}$ & $\begin{array}{c}\text { Trehalose } \\
\text { - NGI }\end{array}$ & $\begin{array}{c}P \\
\text { value }\end{array}$ & $\begin{array}{l}\text { Sucrose - } \\
\text { Twin Glass } \\
\text { Impinger }\end{array}$ & $\begin{array}{c}\text { Sucrose } \\
-\mathrm{NGI}\end{array}$ & $\begin{array}{c}P \\
\text { value }\end{array}$ \\
\hline \multirow[t]{2}{*}{ Capsules } & 1.19 & 1.35 & 0.730 & 7.56 & 15.52 & 0.396 & 11.08 & 7.00 & 0.094 & 5.52 & 10.02 & 0.410 \\
\hline & \pm 0.67 & \pm 0.35 & & \pm 2.88 & \pm 14.26 & & \pm 2.83 & \pm 1.56 & & \pm 1.65 & \pm 8.32 & \\
\hline \multirow[t]{2}{*}{ Device } & 7.15 & 10.2 & 0.083 & 19.58 & 26.82 & 0.411 & 24.76 & 29.18 & 0.455 & 8.23 & 10.84 & 0.217 \\
\hline & \pm 1.72 & \pm 1.51 & & \pm 7.28 & \pm 11.59 & & \pm 2.08 & \pm 9.03 & & \pm 2.84 & \pm 1.23 & \\
\hline \multirow{2}{*}{$\begin{array}{c}\text { Non- } \\
\text { Respirable }\end{array}$} & 64.15 & 74.94 & 0.174 & 26.37 & 26.64 & 0.974 & 19.09 & 30.55 & 0.051 & 38.5 & 47.12 & 0.102 \\
\hline & \pm 5.46 & \pm 9.92 & & \pm 13.38 & \pm 4.04 & & \pm 4.47 & \pm 5.66 & & \pm 2.89 & \pm 6.46 & \\
\hline \multirow[t]{2}{*}{ Respirable } & 27.5 & 13.51 & 0.007 & 46.48 & 31.03 & 0.014 & 45.08 & 33.27 & 0.019 & 47.74 & 32.01 & 0.011 \\
\hline & \pm 3.75 & \pm 3.01 & & \pm 3.81 & \pm 5.17 & & \pm 1.22 & \pm 5.31 & & \pm 0.73 & \pm 6.16 & \\
\hline
\end{tabular}




\section{Discussion}

This study shows several differences between the outcomes of each carrier. These differences were seen in both the twin glass impinger and the NGI. In the twin glass impinger, it is evident that the majority of the mannitol carrier particles appeared to be in the upper chamber $(64.15 \pm 5.46 \%)$, with the lowest percentage in the other three sections $(P=0.003)$ (Table 1). Salbutamol-mannitolcomplex had deposited a greater percentage in the region which is considered non-respirable, particle size diameter $>6.4 \mu \mathrm{m}$. Another observation from Table 1 is that a lower percentage of the drug remained in the capsules. A similar result was obtained when mannitol was used as a carrier in the NGI (Table 2). The majority of the API was deposited in the mouthpiece, induction port, and pre-separator. The first two cups $(74.94 \pm 9.92 \%)$ which are in all regions that would be considered non-respirable (Table 4) collected particles $>4.46 \mu \mathrm{m}$, and barely any API remained in the capsules $(1.35 \pm 0.35 \%)$. The similarity between the two pieces of equipment when tested with mannitol is highlighted in Table 4. Generally, the powder remained in the capsule due to agglomeration. This is more likely to occur in hygroscopic particles. The lack of powder remaining in the capsules with mannitol and the large amount remaining in the capsules with lactose monohydrate is due to mannitol being less hygroscopic than lactose monohydrate. ${ }^{12}$ Furthermore, the higher amount of emitted drug dose can be attributed to the appropriate composition and good flow properties of the mannitol powder. These findings indicate the higher tendency of lactose monohydrate powders to stick to the capsule and DPI device wall compared to mannitol powders. Agglomeration is more likely if the particles were of a smaller size. ${ }^{13}$ Hence, these observations together suggest that the API-mannitol complex forms a larger and coarser particle size diameter than the other carriers. ${ }^{14}$ Further analysis of the different carriers shows that there are similarities between them (Table 1). The respirable percentage of the dose when tested using the twin glass impinger is seen to be similar between three of the four carriers lactose monohydrate, trehalose and sucrose $(46.48 \pm 1.22 \%$, $45.08 \pm 1.22 \%$, and $47.74 \pm 0.73 \%$, respectively) $(P=0.063)$. This is also the case when lactose monohydrate, trehalose, and sucrose were tested using the NGI $(31.03 \pm 5.17 \%, 33.27 \pm 5.31 \%$, and $32.01 \pm 6.16 \%$, respectively $)(P=0.887)$. The totals for each of the three carriers are slightly lower than the twin glass impinger (Table 4). This suggests that any of the three carriers would produce a similar percentage of smaller drug particles, which are able to reach the lower part of the lungs. ${ }^{15}$ In both the apparatus, thelactose monohydrate, and trehalose exhibited small differences in the percentage of non-respirable dose, whereas sucrose showed a much higher percentage in non-respirable dose (Table 4). Although the respirable dose between them was similar the use of sucrose leads to a greater percentage deposited in the mouth and oropharynx region compared to lactose monohydrate and trehalose. ${ }^{16}$

In addition to the variation seeing between the carriers used, differences were also seen between the two apparatus (Table 3 ). Similar amounts of the API were found in the capsules and device; however, there were differences in respirable and nonrespirable regions of each apparatus. The similarities in the results obtained for the capsules and device of both $\mathrm{NGI}$ and twin glass impinger would be expected, as they are independent of the two apparatus. When comparing the API deposited in the respirable section, the $\mathrm{NGI}$ recorded a lower percentage than the twin glass impinger. As mentioned earlier, the sections in the NGI were grouped together to separate them into respirable and non-respirable, in order to compare it to the twin glass impinger. As the cut-off points between the two apparatus are different, 
an assumption was made that any particles $<4.46 \mu \mathrm{m}$ would be considered as a respirable percentage of the dose. The twin glass impinges in comparison considers particles $<6.4 \mu \mathrm{m}$ to be respirable, which does not match with the NGI. As the cut-off point for the NGI is lower than the cut-off point for the twin glass impinger, it can be assumed that a greater percentage of the dose would be considered respirable in the twin glass impinger. This would be due to the twin glass impinger considering particles between the sizes of $4.46-6.4 \mu \mathrm{m}$ to be respirable, whereas the NGI does not. There are several reasons for why the percentage of API left in the capsules was high in some cases. These include the presence of moisture and the particles clumping whilst the powder was initially placed in the capsules. Due to both of these factors, the particles coagulated and could not be sucked out. Another factor may be the absence of an airtight seal between the mouthpiece and device leading to poor suction.

\section{Conclusion}

This study has shown that NGI gives more details regarding the particle size distribution. In comparison, the twin glass impinger produced results which could be considered cruder. The twin glass impinger was easy and quick to use and gave similar results to the NGI. The NGI is more complicated and expensive, but if a specific particle size range is required, it is a more suitable for choice. Both apparatus are applicable for pulmonary drug delivery as indicated by dry powder inhaler testing. There were no significant differences between the respirable fractions of drug using different carriers. The greatest hindrance was the difference in cut-off points between the two apparatus. In order to overcome this problem, the delivery of the powder having uniform particle size distribution could be considered to provide a reference value to estimate the percentage of particles that would be under or over a certain cut-off point.

\section{Competing interests}

The authors declare that they have no competing interests.

\section{References}

1. Hamishehkar $H$, Rahimpour $Y$, Javadzadeh $Y$. The Role of Carrier in Dry Powder Inhaler. In: Recent Advances in Novel Drug Carrier Systems. INTECH; 2012.

2. Rudolf G, Köbrich R, Stahlhofen W. Modelling and algebraic formulation of regional aerosol deposition in man. J Aerosol Sci 1990; 21:S4036.

3. Hallworth GW, Westmoreland DG. The twin impinger: a simple device for assessing the delivery of drugs from metered dose pressurized aerosol inhalers. J Pharm Pharmacol 1987; 39(12):966-72.

4. Meenach SA, Vogt FG, Anderson KW, Hilt JZ, McGarry RC, Mansour HM. Design, physicochemical characterization, and optimization of organic solution advanced spraydried inhalable dipalmitoylphosphatidylcholine (DPPC) and dipalmitoyl phosphatidyl ethanolaminepoly(ethylene glycol) (DPPE-PEG) microparticles and nanoparticles for targeted respiratory nanomedicine delivery as dry powder inhalation aerosols. Int J Nanomedicine 2013; 8:275-93.

5. Wu X, Zhang W, Hayes D, Mansour HM. Physicochemical characterization and aerosol dispersion performance of organic solution advanced spray-dried cyclosporine A multifunctional particles for dry powder inhalation aerosol delivery. Int J Nanomedicine 2013; 8:1269-83.

6. Mohan M, Lee S, Guo C, Peri SP, Doub WH. Evaluation of Abbreviated Impactor Measurements (AIM) and Efficient Data Analysis (EDA) for Dry Powder Inhalers (DPIs) Against the Full-Resolution Next Generation Impactor (NGI). AAPS Pharm Sci Tech 2017; 18(5):1585-94.

7. Mitchell JP, Nagel MW, Wiersema KJ, Doyle CC. Aerodynamic particle size analysis of aerosols from pressurized metered-dose inhalers: comparison of Andersen 8-stage cascade impactor, next generation pharmaceutical impactor, and model 3321 Aerodynamic Particle Sizer aerosol spectrometer. AAPS Pharm Sci Tech 2003; 4(4):E54.

8. Schonell M, Chan-Yeung M, McLean L. Salbutamol--an effective bronchodilator. Can Med Assoc J 1972; 106(4):339-41.

9. LaForce $C$, Taveras $H$, Iverson $H$, Shore $P$. Albuterol multidose dry powder inhaler efficacy and safety versus placebo in children with asthma. Allergy Asthma Proc 2017; 38(1):28-37.

10. Mitchell J, Nagel M. Particle Size Analysis of Aerosols from Medicinal Inhalers. KONA Powder Part J 2004; 22:32-65. 
11. Peng $T$, Lin $S$, Niu $B$, Wang $X$, Huang $Y$, Zhang $X$, et al. Influence of physical properties of carrier on the performance of dry powder inhalers. Acta Pharm Sin B 2016; 6(4):308-18.

12. Ohrem HL, Schornick E, Kalivoda A, Ognibene $\mathrm{R}$. Why is mannitol becoming more and more popular as a pharmaceutical excipient in solid dosage forms? Pharm Dev Technol 2014; 19(3):257-62.

13. Allen E, Smith P, Henshaw J. Review of Particle Agglomeration. US Department of Energy; 2001.

14. Zeng XM, Martin GP, Marriott C, Pritchard J. Lactose as a carrier in dry powder formulations: the influence of surface characteristics on drug delivery. J Pharm Sci 2001; 90(9):1424-34.

15. Pilcer G, Wauthoz N, Amighi K. Lactose characteristics and the generation of the aerosol. Adv Drug Deliv Rev 2012; 64(3):233-56.

16. Sakagami M. In vivo, in vitro and ex vivo models to assess pulmonary absorption and disposition of inhaled therapeutics for systemic delivery. Adv Drug Deliv Rev 2006; 58(9-10):1030-60. 